Gut, 1978, 19, 812-818

\title{
Secretion pattern of secretin in man: regulation by gastric acid $^{1}$
}

\author{
O. B. SCHAFFALITZKY DE MUCKADELL2 AND J. FAHRENKRUG \\ From the Department of Clinical Chemistry, Bispebjerg Hospital, Copenhagen NV, Denmark
}

SUMMARY Median concentration of plasma secretin in the fasting state in 11 achlorhydria patients, 17 normal subjects, eight duodenal ulcer patients, and 11 Zollinger-Ellison patients was $0 \cdot 3,1 \cdot 2,2 \cdot 5$, and $5.9 \mathrm{pmol} \times 1^{-1}$, respectively. Aspiration of gastric acid in normal subjects and duodenal ulcer patients was followed by a significant lowering of the plasma secretin concentration. In normal subjects insulin-induced hypoglycaemia resulted in increased secretin levels when gastric acid was allowed to enter the duodenum, whereas no changes were observed when gastric acid was aspirated. Simultaneous measurements of intraduodenal $\mathrm{pH}$ and plasma secretin concentration in the fasting state and in response to a meal showed that rapid falls in intraduodenal $\mathrm{pH}$ were followed by short-lived increments in plasma secretin concentration. These changes in $\mathrm{pH}$ and in secretin levels were diminished after cimetidine. It is concluded that gastric acid in man does trigger release of secretin and that secretin is secreted intermittently both in the fasting state and in response to a meal when boluses of acid enter the duodenum.

In recent years several radioimmunoassays for secretin have been presented. The assays all measure increased concentrations of secretin in human plasma after intraduodenal infusion of various, often unphysiologically large amounts of acid (Boden and Chey, 1973; Bloom, 1975; Byrnes and Marjason, 1976; O'Connor et al., 1976; Rhodes et al., 1976; Hanssen and Torjesen, 1977; Schaffalitzky de Muckadell and Fahrenkrug, 1977). Intraduodenal acidification is for the moment the only well-established stimulus to secretin release (Boden et al., 1975; Fahrenkrug and Schaffalitzky de Muckadell, 1977; Fahrenkrug et al., 1977). It has, however, been questioned whether the requirements for release of secretin are met in human physiology (Wormsley, 1973) and it has been difficult to demonstrate changes in secretin concentrations in plasma during physiological conditions in man (Rhodes et al., 1976; Fahrenkrug and Schaffalitzky de Muckadell, 1977). If secretin has any significance in human physiology the

${ }^{1}$ This paper was presented in part at 'Symposium on Gut Hormones' in Lausanne, 18-19 June, 1977.

2Address for correspondence: Ove B. Schaffalitzky de Muckadell, Department of Clinical Chemistry, Bispebjerg Hospital, Bispebjerg Bakke 23, DK-2400 Copenhagen NV, Denmark.

Received for publication 10 April 1978 release of the hormone is expected to be dependent on acid in the duodenum.

The present study was therefore undertaken in order to examine the effect of endogenously released gastric acid on plasma secretin concentration in man.

\section{Methods}

Seventeen normal subjects, eight duodenal ulcer patients, 11 unoperated patients with the ZollingerEllison syndrome, and 11 patients with achlorhydria volunteered for the study after the purpose, nature, and possible risks had been carefully explained to them.

In normal subjects (median age 30 years, range 24-63 years, six females) none had any history of gastrointestinal or endocrine disease. In duodenal ulcer patients (age 33 years, range 24-66 years, three females) the diagnosis was based on the demonstration of ulcer by endoscopy and radiological examination. In Zollinger-Ellison patients (age 46 years, range 32-72 years, four females) the diagnosis was established on the basis of classical history, hypersecretion of acid, and hypergastrinaemia of extragastric origin. Achlorhydria was demonstrated by the augmented histamine test, the patients (age 57 years, 37-84 years, eight females) all had pernicious anaemia. 
INVESTIGATIVE PROCEDURES

I. EFFECT OF BASAL SECRETION OF ACID ON PLASMA SECRETIN CONCENTRATION

The effect of basal gastric acid secretion was studied in $\mathbf{1 0}$ of the normal subjects and all of the patients.

In normal subjects and duodenal ulcer patients a nasogastric tube was introduced after an overnight fast and the position of the tube checked by fiuoroscopy. Blood samples were drawn from a peripheral vein $20,17 \cdot 5,15,12 \cdot 5,10,7 \cdot 5,5,2 \cdot 5$, and 0 minutes before and $10,12 \cdot 5,15,17 \cdot 5,20,22 \cdot 5,25$, $27 \cdot 5$, and 30 minutes after the start of gastric acid aspiration. Intermittent machine suction (Egnell, Sweden) was used for the aspiration which lasted for 30 minutes. In six of the normal subjects additional samples were drawn $10,12 \cdot 5,15,17 \cdot 5,20,22 \cdot 5,25$, $27 \cdot 5$, and 30 minutes after cessation of gastric aspiration.

In Zollinger-Ellison patients two samples and in achlorhydria patients four samples were drawn with 10 minute intervals after an overnight fast.

\section{EFFECT OF STIMULATED GASTRIC ACID SECRETION ON CONCENTRATION OF SECRETIN IN PLASMA}

\section{Insulin test}

In six normal, fasting subjects hypoglycaemia was induced by the intravenous injection of $0.2 \mathrm{IU}$ insulin (Insulin Leo(R) Neutral, Nordisk insulin laboratorium, Denmark) per kg body weight. Each subject was studied twice with seven days' interval. In one experiment gastric acid was allowed to enter the duodenum and in the other gastric acid was aspirated and secretion rate of acid measured. Blood samples for determination of plasma glucose and plasma secretin concentration were drawn from a peripheral vein 15 and 0 minutes before and $15,30,45,60,75$, and 90 minutes after injection of insulin.

\section{Meal test}

Plasma secretin concentration and intraduodenal pH were measured simultaneously in seven normal subjects, before, during, and after ingestion of a meal consisting of $200 \mathrm{~g}$ beefsteak, sauce, vegetables, and a beer. A glass electrode (Radiometer glass electrode-calomel electrode system GK 282 C) (Rune, 1968) was positioned under fluoroscopic control in the upper second part of the duodenum, pH was read on a pH-meter 26 (Radiometer, Copenhagen, Denmark) and continuously recorded. The position of the glass electrode was checked by fluoroscopy before every blood sample was drawn or at least at five minute intervals. The electrode system was calibrated at $\mathrm{pH} 2.00$ and 7.41 and controlled at $\mathrm{pH} 4.00$ before each experiment and the calibration was checked after the experiment. Blood samples were drawn from a peripheral vein at two to 10 minute intervals.

In four of the subjects an additional experiment was performed: $400 \mathrm{mg}$ (two tablets) cimetidine (Smith, Kline, and French, UK) were given 30 minutes before introducing the glass electrode and another $200 \mathrm{mg}$ were given together with the meal. Two hours after the meal $40 \mathrm{ml} 0.1 \mathrm{~mol} \times 1^{-1}$ hydrochloric acid was infused into the duodenum over three minutes through a thin polyethylene tube attached to the $\mathrm{pH}$ electrode. Blood samples were drawn 10, five, and 0 minutes before and five and $\mathbf{1 0}$ minutes after the start of the infusion.

\section{Gel-permeation-chromatography studies}

The antiserum used contains an antibody population reacting with different sequences at the secretin molecule (Fahrenkrug et al., 1976). To ensure that the detected values are due to measurements of intact secretin molecules, gel-permeation-chromatography of plasma samples was performed. Samples of $90 \mathrm{ml}$ human plasma obtained in the fasting state and during intraduodenal acidification and one sample of $50 \mathrm{ml}$ porcine plasma were treated as follows: plasma was extracted with ethanol as previously described (Schaffalitzky de Muckadell and Fahrenkrug, 1977) and dried under vacuum. The dried product was dissolved in $10 \mathrm{ml}$ of 0.5 mol $\times 1^{-1}$ acetic acid and lyophilised. The sample was then dissolved in $2 \mathrm{ml}$ of elution buffer, mixed with trace amounts of 125 I-labelled albumin and ${ }^{22} \mathrm{Na}$. One millilitre was applied to Sephadex G-50 superfine columns $(11 \times 1000 \mathrm{~mm})$ calibrated with pure natural porcine secretin (GIH, Stockholm). The columns were eluted with $\mathrm{NH}_{4} \mathrm{HCO}_{3}$ solution $\left(0.25 \mathrm{~mol} \times 1^{-1}\right)$ containing $72.5 \mu \mathrm{mol}$ of human albumin and $200000 \mathrm{kIU}$ of aprotinin (Trasylol ${ }^{(\mathrm{R})}$ ) per litre at $4^{\circ} \mathrm{C}$. Ten minutes' fraction was collected and assayed.

\section{Laboratory analyses}

Plasma secretin was measured after extraction with ethanol as previously described (Schaffalitzky de Muckadell and Fahrenkrug, 1977) except that sample volume was increased to $800 \mu \mathrm{l}$ in order to increase the sensitivity of the assay. Antiserum 5595-3 (Fahrenkrug et al., 1976) was used and hormone free plasma (plasma blanks) was prepared from every subject (in the meal test both fasting and postprandial plasma were used). All samples were assayed in triplicate. The detection limit of the assays used, calculated from the slope of standard curves and precision in the determination of response 
metameter at zero hormone concentration (Ekins and Newman, 1970), was 0.5 pmol per litre sample. With correction for extraction recovery, the lowest plasma secretin concentration to be distinguished from zero with $95 \%$ confidence by means of a triple determination was $0.6 \mathrm{pmol}$ per litre plasma. The theoretically attainable sensitivity of the assay (Ekins and Newman, 1970) is 0.1 pmol per litre plasma. The extraction recovery of plasma samples obtained from different individuals did not differ significantly. Analytical precision of the assays used was checked as follows: 30 of the blood samples were divided into two and the secretin concentration determined in each portion.

Between assay variation (15 assays) calculated from 15 duplicate samples was $0.6 \mathrm{pmol} \times 1^{-1}(\mathrm{SD})$ at a level of $4.8 \mathrm{pmol} \times 1^{-1}$ and within assay variation (15 duplicates) was $0.3 \mathrm{pmol} \times 1^{-1}(\mathrm{SD})$ at a level of $1.8 \mathrm{pmol} \times 1^{-1}$.

Plasma glucose was measured by a glucose-oxidase method (Trinder, 1969). Aspirated gastric acid was titrated with $0.1 \mathrm{~mol} \times 1^{-1} \mathrm{NaOH}(\mathrm{pH}$ meter PHM 26, Titrator 11, Autoburette ABU 12, Radiometer, Copenhagen, Denmark) to $\mathrm{pH} 3 \cdot 5$.

\section{Calculations and statistical analyses}

With an operational detection limit (defined as above) of $0.6 \mathrm{pmol} \times 1^{-1}$ the assay does not allow a differentiation of values less than $0.6 \mathrm{pmol} \times 1^{-1}$ apart. However, the slope of standard curves and the precision in determination of response metameter is constant within the range of concentrations from zero to $5 \mathrm{pmol} \times 1^{-1}$, and for that reason a figure between $0.1-0.6 \mathrm{pmol} \times 1^{-1}$ is estimated with the same confidence as a figure above 0.6 pmol $\times 1^{-1}$ (but below $\left.5 \mathrm{pmol} \times 1^{-1}\right)$. The secretin concentrations read from the standard curve were therefore used for calculations whether the figure was below operational detection limit or not, as the read value is a better estimate of the true concentration than statements like 'zero, equal to detection limit, or unmeasurable.'

Measured values-that is, the difference between sample and blank-were positive in all normal subjects, duodenal ulcer patients, and ZollingerEllison patients. In achlorhydria patients occasional negative values (within the range expected from estimate of detection limit) were found. Negative values were included in the calculations of individual medians.

In the study of fasting levels in achlorhydria patients, normal subjects, duodenal ulcer patients, and Zollinger-Ellison patients individual median secretin concentration was calculated on the basis of four, nine, nine, and two triplicate determinations respectively. Individual median secretin concentra- tions following gastric aspiration in normal subjects and duodenal ulcer patients were also based on nine triplicate determinations.

Statistical analyses were performed by the Mann Whitney U-test, Wilcoxon matched-pairs signedranks test, and the Friedman two-way analysis of variance (Siegel, 1956). Results are given, if nothing else is indicated, as medians followed by total ranges in parentheses. The level of statistical significance was 0.05 .

\section{Results}

\section{FASTING LEVELS OF SECRETIN}

In the 10 normal subjects, and eight duodenal ulcer patients, aspiration of gastric acid was followed by a significant lowering of the concentration of secretin in plasma (Fig. 1).

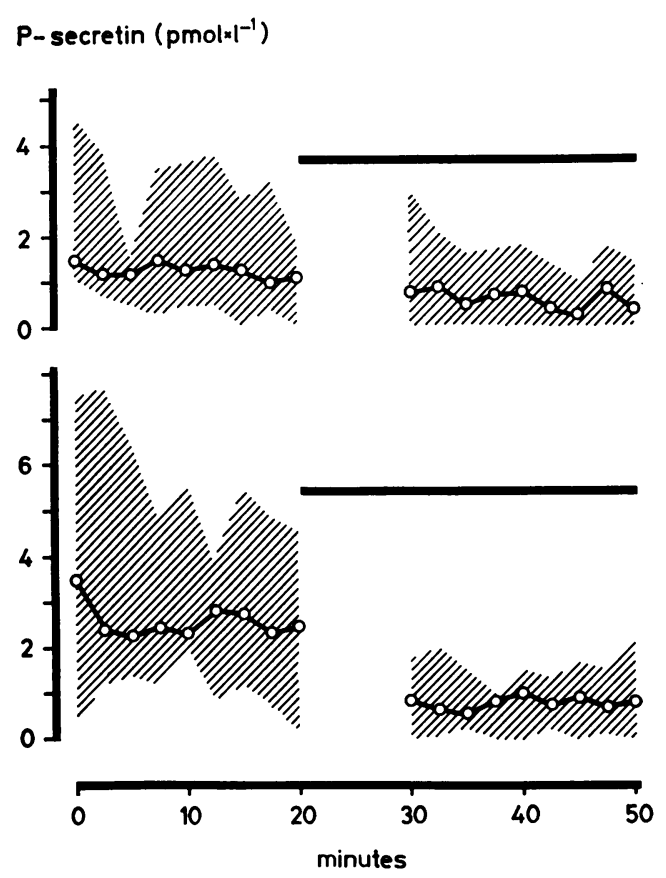

Fig. 1 Median concentration and total ranges (hatched area) of secretin in plasma of 10 normal subjects (upper panel) and eight duodenal ulcer patients (lower panel) before and during aspiration of gastric acid (horizontal bar).

In the group of normal subjects individual median secretin concentration before aspiration ranged from 0.9 to $2.8 \mathrm{pmol} \times 1^{-1}$ with a median of $1.3 \mathrm{pmol} \times 1^{-1}$; median intra-individual range was $1.6(1 \cdot 1-3 \cdot 2)$ pmol $\times 1^{-1}$. Compared to normal subjects duodenal ulcer patients had significantly 
higher fasting levels of secretin; individual median secretin concentration ranged from 2.0 to $4.8 \mathrm{pmol}$ $\times 1^{-1}$ with a median of $2.5 \mathrm{pmol} \times 1^{-1}$; median intra-individual range was $3.8(1 \cdot 8-6 \cdot 0) \mathrm{pmol} \times 1^{-1}$.

Median post-aspiration levels in the group of normal subjects and duodenal ulcer patients did not differ significantly, the values being 0.5 and $0.8 \mathrm{pmol} \times 1^{-1}$, respectively. After gastric aspiration individual median values ranged from 0.2 to 1.4 pmol $\times 1^{-1}$ both in normal subjects and in duodenal ulcer patients. In this period median intra-individual ranges were $1.4(0.9-2.9)$ and $1.6(0.8-2 \cdot 2) \mathrm{pmol}$ $\times 1^{-1}$, respectively.

In the group of six subjects in whom additional blood samples were drawn after cessation of gastric aspiration median concentration of secretin decreased significantly from $1.2(0.9-2.0) \mathrm{pmol} \times 1^{-1}$ to $0.5(0.2-1.4) \mathrm{pmol} \times 1^{-1}$ after aspiration and increased significantly to $1.9(1.0-2.8) \mathrm{pmol} \times 1^{-1}$ after aspiration ended.

In achlorhydria patients median concentration of secretin was $0.3(0.0-1 \cdot 6) \mathrm{pmol} \times 1^{-1}$; this value does not differ significantly from zero or postaspiration secretin levels in normal subjects and duodenal ulcer patients, but is significantly lower than median secretin level found in normal fasting subjects before aspiration of gastric acid. In Zollinger-Ellison patients median concentration of secretin in plasma was $5.9(2.7-10.4) \mathrm{pmol} \times 1^{-1}$, which is significantly higher than the median level found in duodenal ulcer patients.

Basal secretion rate of gastric acid in normal subjects, duodenal ulcer patients, and ZollingerEllison patients was $3 \cdot 0(0 \cdot 6-11 \cdot 4), 5 \cdot 5(1 \cdot 6-14 \cdot 2)$, and $32.4(20 \cdot 2-120 \cdot 0) \mathrm{mmol} \times \mathrm{h}^{-1}$ respectively. In this respect the difference between normal subjects and duodenal ulcer patients was not statistically significant, whereas basal acid output was significantly higher in Zollinger-Ellison patients than in duodenal ulcer patients.

INSULIN-INDUCED HYPOGLYCAEMIA (Fig. 2)

Basal glucose concentration was $4 \cdot 6$ (4.4-5.4) mmol $\times 1^{-1}$, and nadir concentration, $1.5(1 \cdot 2-1 \cdot 7)$ mmol $\times 1^{-1}$, was reached 30 minutes after insulin injection. The concentration of glucose in plasma was not affected by gastric aspiration.

Secretion rate of gastric acid was 3.4 (2.0-11.8) $\mathrm{mmol} \times \mathrm{h}^{-1}$ in the basal state and reached a maximum of $32 \cdot 2(25 \cdot 6-39 \cdot 2) \mathrm{mmol} \times \mathrm{h}^{-1}$ after 60-75 min.

The concentration of secretin in plasma increased significantly when acid was allowed to enter the duodenum. The fasting levels ranged from 0.2 to $2.2 \mathrm{pmol} \times 1^{-1}$ with a median of $1.4 \mathrm{pmol} \times 1^{-1}$. A maximum of $8.6 \mathrm{pmol} \times 1^{-1}(6 \cdot 6-15 \cdot 8)$ was
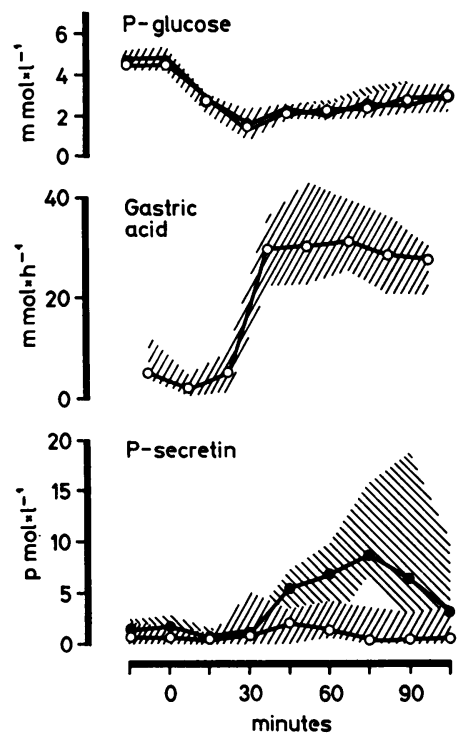

Fig. 2 Median concentration of glucose and secretin in plasma and median gastric acid output of six normal subjects before and during hypoglycaemia induced by intravenous injection of 0.2 IU insulin per $\mathrm{kg}$ body weight. With $(\mathrm{-} \bigcirc)$ and without (-) aspiration of gastric acid. Abscissa: minutes after injection of insulin. Hatched area: total ranges.

reached 75 minutes after injection of insulin.

No significant changes in secretin levels occurred after stimulation with insulin when gastric acid was aspirated.

MEAL TEST (Figs. 3 and 4)

In every subject rapid falls in duodenal $\mathrm{pH}$ were followed by increments in plasma secretin concentration both in the fasting state and after the meal. Peak concentrations of secretin were observed two to five minutes after the fall in $\mathrm{pH}$. Thus secretin was released intermittently at various intervals. In the fasting state individual median concentration of secretin ranged from 0.5 to $2.0 \mathrm{pmol} \times 1^{-1}$ with a median of $1.2 \mathrm{pmol} \times 1^{-1}$ and the $\mathrm{pH}$ spikes occurred with 15 (three to 45 ) minute intervals. Postprandially the pH-spikes occurred with eight (two to 25) minute intervals and secretin concentrations increased significantly; individual median concentration of secretin in plasma ranged from 0.8 to $3.0 \mathrm{pmol} \times 1^{-1}$ with a median of $1.8 \mathrm{pmol}$ $\times 1^{-1}$. Postprandial individual maximum values ranged from 2.6 to $6.8 \mathrm{pmol} \times 1^{-1}$ with a median of $3.6 \mathrm{pmol} \times 1^{-1}$. Cimetidine suppressed the changes in intraduodenal $\mathrm{pH}$ as well as in plasma secretin levels (Fig. 4). 

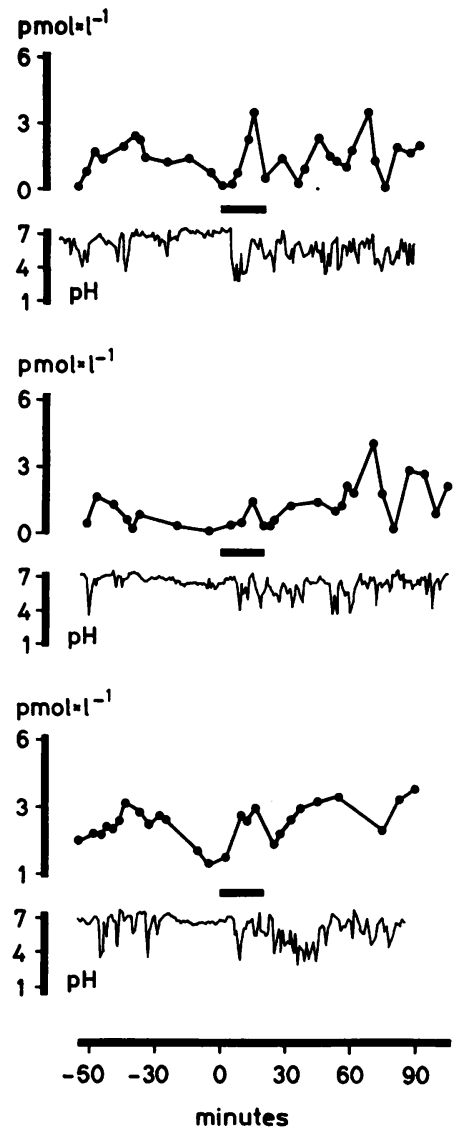

Fig. 3 Individual concentration of secretin in plasma and intraduodenal $\mathrm{pH}$ of three normal subjects before, during, and after a meal (horizontal bar).

Integrated secretin concentration-that is, the area below the curve of secretin concentrationdivided by the observation time was $0.9(0.7-2.0)$ pmol $\times 1^{-1}$ in the fasting state and increased significantly to $1.7(0.9-3 \cdot 1) \mathrm{pmol} \times 1^{-1}$ after the meal. Cimetidine significantly reduced the integrated concentration of secretin both in the fasting state and postprandially to $0.7(0.5-1.0)$ pmol $\times 1^{-1}$ and $0.7(0.6-1.5) \mathrm{pmol} \times 1^{-1}$, respectively. The secretin response to duodenal acidification by exogenous acid after cimetidine, however, was similar to earlier results without cimetidine, the concentration of secretin being $18.3(11 \cdot 8-20.2) \mathrm{pmol} \times 1^{-1}$ five minutes after infusion of acid (normal range 4.5-23.6 pmol/1 (Schaffalitzky de Muckadell and Fahrenkrug, 1978)). The pH electrode was stable throughout the experiment, the difference between first and last $\mathrm{pH}$ control measurement being 0.0 $(-0 \cdot 1$ to $0 \cdot 1)$.
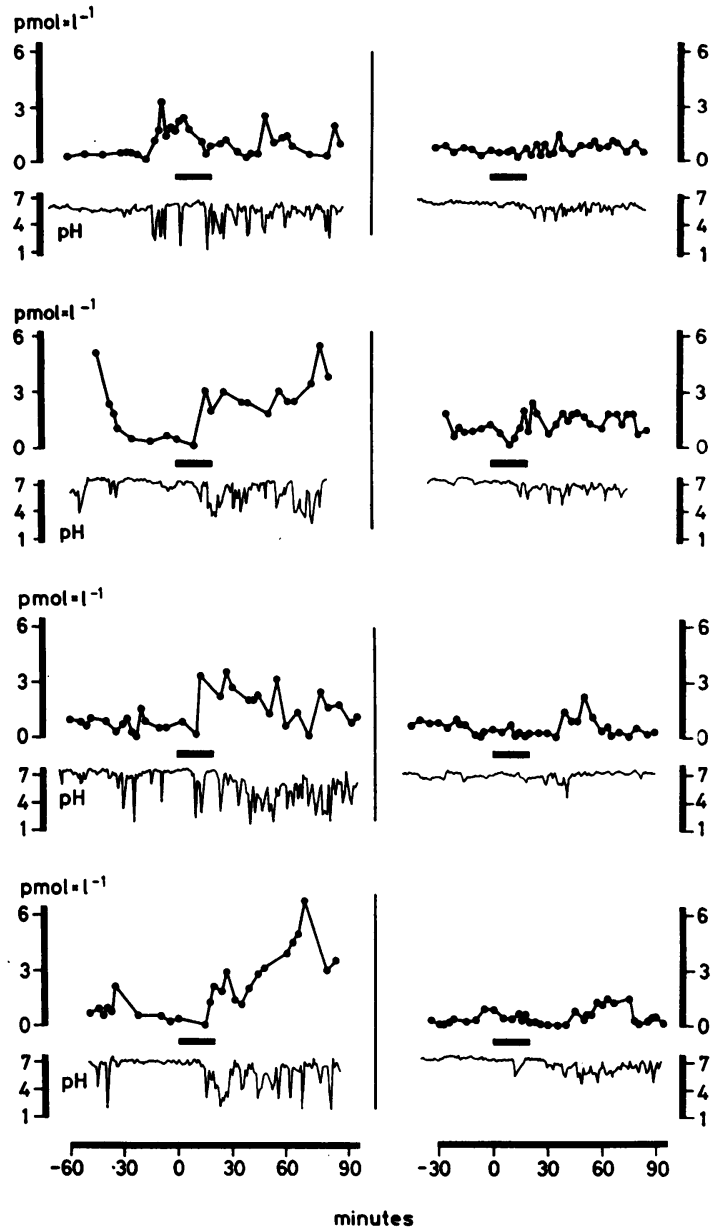

Fig. 4 Individual concentration of secretin in plasma and intraduodenal pH of four normal subjects before, during, and after a meal (left panel). An additional experiment (right panel) was performed in the same subjects after cimetidine.

\section{GEL-PERMEATION-CHROMATOGRAPHY STUDIES}

These studies (Fig. 5) demonstrated that the used antiserum only detects one component of secretin in human and porcine plasma and that the elution position is identical with that of pure natural porcine secretin (used as standards in the secretin assay).

\section{Discussion}

The present study has shown that the plasma secretin concentration in man is regulated by endogenous acid and that secretin under physiological conditions is secreted in minute short-lived 


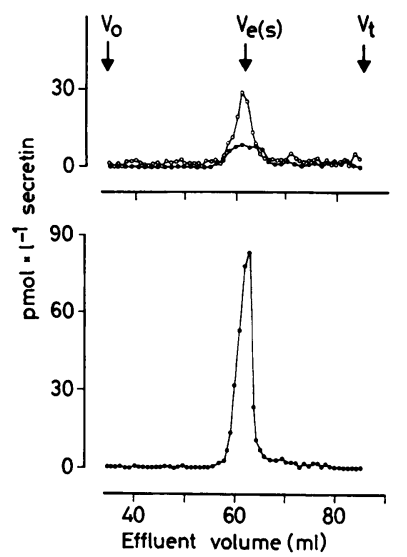

Fig. 5 Elution diagram of secretin immunoreactivity from plasma samples. Results from gel-permeation-chromatography on a $11 \times 1000 \mathrm{~mm}$ Sephadex G-50 superfine column calibrated with ${ }^{125}$ I-labelled albumin, pure natural porcine secretin, and ${ }^{22} \mathrm{Na}$. Upper panel: human fasting plasma (৩) and human plasma obtained during intraduodenal acidification $(\bigcirc)$. The concentration of secretin in the plasma samples were $3 \cdot 1$ and $11 \cdot 1$ pmol $\times 1^{-1}$ respectively. Lower panel: porcine plasma (secretin concentration $20.7 \mathrm{pmol} \times 1^{-1}$ ) obtained during intraduodenal acidification. $V_{0}$, Void volume; $V_{\mathrm{e}(\mathrm{s})}$, elution position of pure natural porcine secretin; $V_{\mathrm{t}}$, total mobile phase.

spikes. The influence of gastric acid on the fasting secretin concentration is clearly demonstrated by comparing the secretin levels in the four groups of acid secretors. The influence of gastric juice is further substantiated by the decline in secretin levels after gastric aspiration in normal subjects and duodenal ulcer patients. In these studies the concentration of secretin in plasma did not reach zero, probably because of incomplete aspiration of acid, since the median secretin concentration in pernicious anaemia patients was indistinguishable from zero.

In previous reports (Bloom and Ward, 1975; Isenberg et al., 1977; Schaffalitzky de Muckadell and Fahrenkrug, 1977) secretin levels in duodenal ulcer patients were lower than or equal to the values found in normal controls, whereas higher levels were found in the present study. This discrepancy is most probably explained by the more precise estimate of basal levels in the present study, as the values are based on nine samples drawn with short intervals from each person and the present assay is perhaps more sensitive than other secretin assays.

The maximum median concentration of secretin found after insulin-induced hypoglycaemia was
$8.6 \mathrm{pmol} \times 1^{-1}$. This figure is in fair accord with those observed in normal human subjects after intraduodenal instillation of $23-45 \mathrm{mmol}$ hydrochloric acid per hour (Isenberg et al., 1977). In our study the median peak secretion of acid was $32 \cdot 2$ mmol $\times \mathrm{h}^{-1}$ when gastric acid was aspirated, this rate of secretion, however, is probably higher than the secretion during the experiments in which gastric content was allowed to enter the duodenum, as the presence of acid in the duodenum is known to inhibit gastric secretion (Johnston and Duthie, 1964). Thus the determination of acid load is inaccurate and the results not directly comparable.

The unchanged secretin levels found after insulin-induced hypoglycaemia with aspiration of acid suggest that vagal activity by itself has no effect on the release of secretin.

The results of the meal test demonstrate that secretin both in the fasting state and during the meal is released intermittently when boluses of acid enter the duodenum. The timing of secretin release varies from individual to individual and for that reason intra-individual changes instead of median or mean changes were studied. The intermittent release of secretin explains the considerable fluctuations that were observed in the study of fasting levels (Fig. 1) in which intra-individual variation in secretin concentration during the 20 minute basal period were several times greater than analytical variation. The changing fasting levels and different timing in secretin release might in part explain the previous difficulties in demonstrating an effect of a meal on mean plasma secretin concentration at fixed time points in groups of normal subjects (Rhodes et al., 1976; Fahrenkrug and Schaffalitzky de Muckadell, 1977).

Another explanation is that the sensitivity of most assays has been inadequate to detect the small rises in secretin concentration.

The short-lived changes in intraduodenal $\mathrm{pH}$ merely indicate the time at which acid enters into that part of the duodenum and is not necessarily correlated to acid load and the length of intestine acidified-that is, the intensity of stimulation. Furthermore, it is unlikely that the $\mathrm{pH}$ value measured is identical with the $\mathrm{pH}$ at the surface of the stimulated secretin cells. Thus it is not possible in these studies to determine the $\mathrm{pH}$-threshold for release of secretin.

It was not possible to maintain the position of glass-electrode in the first part of the duodenum during a meal and an acidification of the most proximal part of the duodenum without a concomitant detectable fall in $\mathrm{pH}$ in the second part can therefore not be excluded. However, the results (Figs. 3 and 4) indicate that, if only the duodenal 
bulb had been exposed to acid, secretin response would be minute if detectable, as all rises were preceded by a fall in intraduodenal $\mathrm{pH}$.

The increments in secretin concentration during the spikes were small and consequently the question arises whether these changes are sufficient to stimulate pancreatic secretion of bicarbonate. A constant infusion of natural porcine (GIH) secretin in a dose which increases the plasma secretin level from 0.6 to $2.3 \mathrm{pmol} \times 1^{-1}$ has been shown to increase bicarbonate secretion into the duodenum from 0.41 to $3.68 \mathrm{mmol} \times \mathrm{h}^{-1}$ (Schaffalitzky de Muckadell et al., 1978). Still, the effectiveness of intermittently released secretin on pancreatic bicarbonate secretion mimicked by intravenous injections of small boluses of exogenous secretin needs to be investigated.

The skilful technical assistance of Hanne Dam, Lene Linnet, Lene Poulsen, Nina Rasmussen, and Anne Sylvest is gratefully acknowledged. The laboratory staff, Surgical Department F, is thanked for great helpfulness. The study was supported by grants from the Danish Medical Research Council (J. nr. 512-5273, 512-8150) and the Danish Hospital Foundation for Medical Research, Region of Copenhagen, The Faroe Islands, and Greenland (J. nr. 76/77 46).

\section{References}

Bloom, S. R. (1975). The development of a radioimmunoassay for secretin. In Gastrointestinal Hormones: $A$ Symposium, pp. 257-268. Edited by J. C. Thompson. University of Texas Press: Austin.

Bloom, S. R., and Ward, A. S. (1975). Failure of secretin release in patients with duodenal ulcer. British Medical Journal, 1, 126-127.

Boden, G., and Chey, W. Y. (1973). Preparation and specificity of antiserum to synthetic secretin and its use in a radioimmunoassay (RIA). Endocrinology, 92, 1617-1624.

Boden, G., Essa, N., and Owen, O. E. (1975). Effects of intraduodenal amino acids, fatty acids, and sugars on secretin concentrations. Gastroenterology, 68, 722-727.

Byrnes, D. J., and Marjason, J. P. (1976). Radioimmunoassay of secretin in plasma. Hormone and Metabolic Research, 8, 361-365.

Ekins, R., and Newman, B. (1970). Theoretical aspects of saturation analysis. Acta Endocrinologica, suppl. 147, 11-37.
Fahrenkrug, J., and Schaffalitzky de Muckadell, O. B. (1977). Plasma secretin concentration in man: Effect of intraduodenal glucose, fat, amino acids, ethanol, $\mathrm{HCl}$, or ingestion of a meal. European Journal of Clinical Investigation, 7, 201-203.

Fahrenkrug, J., Schaffalitzky de Muckadell, O. B., and Holst, J. J. (1977). Plasma secretin concentration in anaesthetized pigs after intraduodenal glucose, fat, amino acids or meals with various pH. Scandinavian Journal of Gastroenterology, 12, 273-279.

Fahrenkrug, J., Schaffalitzky de Muckadell, O. B., and Rehfeld, J. F. (1976). Production and evaluation of antibodies for radioimmunoassay of secretin. Scandinavian Journal of Clinical and Laboratory Investigation, 36, 281-287.

Hanssen, L. E., and Torjesen, P. (1977). Radioimmunoassay of secretin in human plasma. Scandinavian Journal of Gastroenterology, 12, 481-488.

Isenberg, J. I., Cano, R., and Bloom, S. R. (1977). Effect of graded amounts of acid instilled into the duodenum on pancreatic bicarbonate secretion and plasma secretin in duodenal ulcer patients and normal subjects. Gastroenterology, 72, 6-8.

Johnston, D., and Duthie, H. L. (1964). Effect of acid in the duodenum on histamine-stimulated gastric secretion in man. Gut, 5, 573-580.

O'Connor, F. A., Buchanan, K. D., Connon, J. J., and Shahidullah, M. (1976). Secretin and insulin: Response to intraduodenal acid. Diabetologica, 12, 145-148.

Rhodes, R. A., Tai, H. H., and Chey, W. Y. (1976). Observations of plasma secretin levels by radioimmunoassay in response to duodenal acidification and to a meat meal in humans. American Journal of Digestive Diseases, 21, 873-879.

Rune, S. J. (1968). An electrode for pH measurement in the gastrointestinal tract. Scandinavian Journal of Gastroenterology, 3, 91-94.

Schaffalitzky de Muckadell, O. B., and Fahrenkrug, J. (1977). Radioimmunoassay of secretin in plasma. Scandinavian Journal of Clinical and Laboratory Investigation, 37, 155-162.

Schaffalitzky de Muckadell, O. B., and Fahrenkrug, J. (1978). Secretin: Role in man. In Gut Hormones, pp. 197-200. Edited by S. R. Bloom. Churchill Livingstone: Edinburgh.

Shaffalitzky de Muckadell, O. B., Fahrenkrug, J., WattBoolsen, S., and Worning, H. (1978). Pancreatic response and plasma secretin concentration during infusion of low dose secretin in man. Scandinavian Journal of Gastroenterology, 13, 305-311.

Siegel, S. (1956). Non Parametric Statistics for the Behavioral Sciences. McGraw-Hill; New York.

Trinder, P. (1969). Determination of glucose in blood using glucose oxidase with an alternative oxygen acceptor. Annals of Clinical Biochemistry, 6, 24-27.

Wormsley, K. G. (1973). Is secretin secreted? Gut, 14, 743-751. 